* Corresponding author

Phone +421556022469

E-mail address:zdenko.bobovsky@tuke.sk

(Ing. Zdenko Bobovský, PhD.)

Article information

Article history: AMS-Volume16-No.4-00158-12

Received 16 June 2012

Accepted 11 August 2012

\section{Simulation Model of Mobile Roboton whith Lengthwise Divided Chassis}

\author{
František Trebuňa*, Lubica Miková
}

Department of Applied Mechanics and Mechatronics, Faculty of Mechanical Engineering, Letná 9, 04200 Košice, Slovak Republic

\section{BIOGRAPHICAL NOTES}

Dr.h.c. mult. prof. Ing. František Trebuňa, CSc. is a professor of applied mechanics, Head of the Department of Applied Mechanics and Mechatronics and Dean of the Faculty of Mechanical Engineering. He is author of 10 monographs, 12 university textbook, special book publications, 12 university notebooks and more than 300 publications in journals and conference proceedings at Slovakia abroad. He is author of important projects and engineering works. He received several prizes at home and abroad. He received three titles Doctor Honoris Causa (DHC) including two from foreign universities for the development of applied mechanics and mechatronics.

Ing. Lubica Miková, PhD. areceived M.S. degree in mechatronics from Technical University of Košice in 2007 and Ph.D. degree in Mechatronics from Technical University of Košice, Slovakia in 2011. She is a researcher of the Department of Applied Mechanics and Mecharonics at the Faculty of Mechanical Engineering at the Technical University of Košice, Slovakia. Her research interests include mechatronics systems and robotics. She has authored more than 17 journal and conference papers on these topics.

\section{KEYWORDS}

Robot kinematics, mobile robots, simulation.

\begin{abstract}
This article is about designing and constructing a four-wheel chassis. Analyzed is a used concept of chassis motion control of mechatronic systems on the principle of differential wheel control for the task of active tracking of planned chassis path. Created was a simulation model of chassis mobile system in terms of kinematics, which will be usable in concept of chassis locomotion control on diverse terrain. A model is also required for examining behavior of chassis on diverse terrain, for examining the influence of dimensions on chassis behavior during crossing over roughness of terrain.
\end{abstract}

\section{Introduction}

One of the main features of mechatronic approach to designing advanced products is complex understanding of the technical object and its computer modeling. The kinematic description of mechanical system issue from an abstraction - simplification of reality.

In simulation model we integrate mechanical, electrical and control subsystem and thus acquire information about their mutual interactions. If we model mechanical and electrical elements as systems with centralized parameters, then it is possible to say, that drawing up the model of mechanical part is clearly the most difficult. 


\section{Concept of GTR 2010}

WGTR 2010 poses a solution of four-wheel chassis with autonomous wheel drive $4 \times 4$ designed for diverse terrain. It has two degrees of freedom, i.e. linear and rotational motion.

It is possible to use it for various tasks such as inspection of automobile chassis and explosives disposal, pipeline, telecommunication and cable network installation, manipulation with dangerous materials, tactical tasks in fight against terrorists and so on. The device should also be used in educating students from mechatronics and engineering fields of study.

Chassis frame is composed of two pieces connected by a passive joint. [14]. Robot chassis has a four-wheel drive that does not lose traction even on diverse terrain surface thanks to the passive joint It enables both parts of frame to randomly tilt depending on terrain difficulty. Hence it is achieved that every wheel in any moment keeps contact with terrain surface [2].

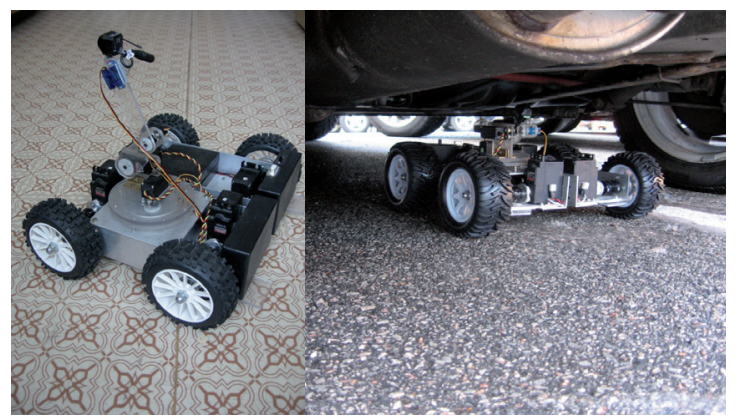

Fig. 1: Mobile robot GTR 2010.

Technical parameters of functional chassis GTR 2010 model:

wheel base: $190 \mathrm{~mm}$,

- gauge: $370 \mathrm{~mm}$,

- inner diameter: $30 \mathrm{~mm}$,

- total mass: $3 \mathrm{~kg}$,

maximal loading capacity: $10 \mathrm{~kg}$,

average motion velocity: $0,3 \mathrm{~m} / \mathrm{s}$.

\section{Control Concept}

The designed chassis uses for its motion differential method of wheel control. Chassis motion should be stable and fluent to avoid slipping between wheels and terrain and to avoid mechanical shock resulting from rapid changes in chassis motion. However during chassis motion unavoidable trajectory deviations between current position and requested trajectory do occur because of path tracking control imperfection using wheels velocity and fault variables from environment (terrain roughness, friction forces changes between wheels and terrain and so forth) $[7,8,9]$.

Trajectory deviations should be corrected online using requested linear and rotational chassis motion velocities by path tracking control $[5,11]$.

In work [7] layout of kinematic control is designed, comprising of three levels of links (dynamic, kinematic and planning). This approach is similar to those, which are applied in robotic manipulators.

\section{Kinematic Model}

Creation of kinematic model was based on mobile robot GTR 2010, which was designed and constructed in department of applied mechanics, and also on experience from previous model GTR2006.

Chassis with four wheels is controlled differentially. Each one of the wheels is independently driven by separate speed servomechanism [10].

Mobile robot always moves in circular trajectory with diameter $\mathrm{R}$ (on trajectory projection of which on plane $X Y$ is circle). Direct motion occurs when trajectory radius approaches infinity. This radius changes in time depending on desired motion direction [1].

Axes of all wheels have to intersect in one point and that point is an immediate center of rotation [2].

In this case it is difficult to draw up a kinematic model of chassis using common methods, because in the center of gravity there is a joint that enables

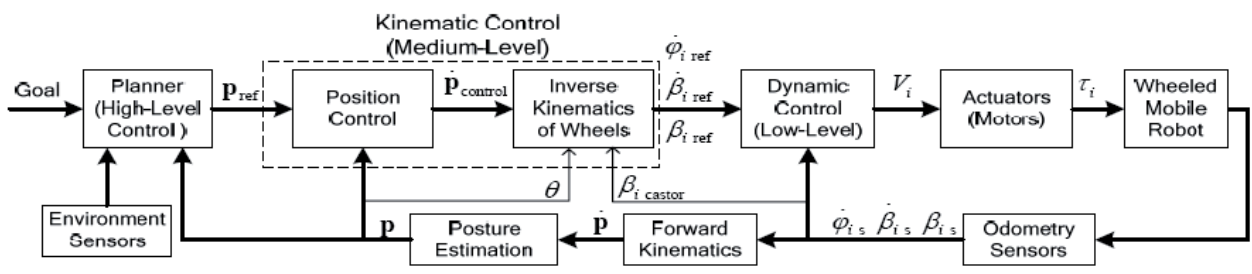

Fig. 2: Control scheme of the wheeled mobile robot [7]. 
chassis to better overcome terrain roughness. For description of resulting kinematic variables, such as position and velocity of chassis center of gravity, or positions and velocities of individual wheels, we used transformation matrices [1].

In general cases it is very difficult to directly find matrix of direction cosines and beginning accompaniments. It is however possible to essentially simplify by motion decomposition to a sequence of simple motions composed of so called basic motions [6].

Decompositions such as these are natural component of practically every task layout about body motion. So called matrix kinematics method is effective and general method for solving body motion and basically whole kinematics [4].

Transformation corresponding to shift in axes $x, y, z$, or transformation corresponding to rotation around defined axes represents coordinate qi $[12,13]$.

Kinematic model of chassis takes into account real dimensions of GTR2010 robot.

Distance between wheel 1 and geometric center of gravity of chassis in direction of axis $x$ is $c=-175$ $\mathrm{mm}$ and in direction of axis $\mathrm{y}$ is $\mathrm{a}=95 \mathrm{~mm}$.

Resulting transformation matrix of wheel 1 position and rotation to geometric center of gravity of chassis:

$T_{b 5}(q 1, q 2, q 3, q 4)=\left[\begin{array}{ccc}\cos (q 1) & -\cos (q 4 / 2) * \sin (q 1) & \sin (q 4 / 2) * \sin (q 1) \\ \sin (q 1) & \cos (q 4 / 2) * \cos (q 1) & -\sin (q 4 / 2) * \cos (q 1) \\ 0 & \sin (q 4 / 2) & \cos (q 4 / 2) \\ 0 & 0 & 0\end{array}\right.$

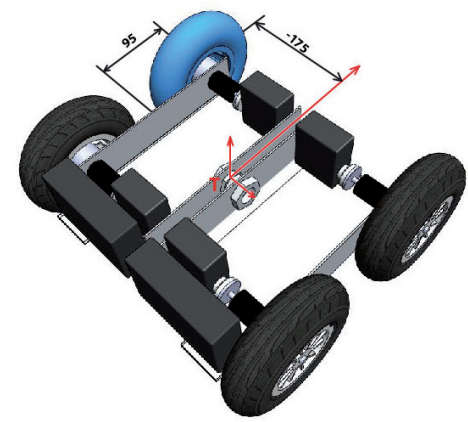

Fig. 5: Position of wheel 1 from geometric center of gravity of chassis.

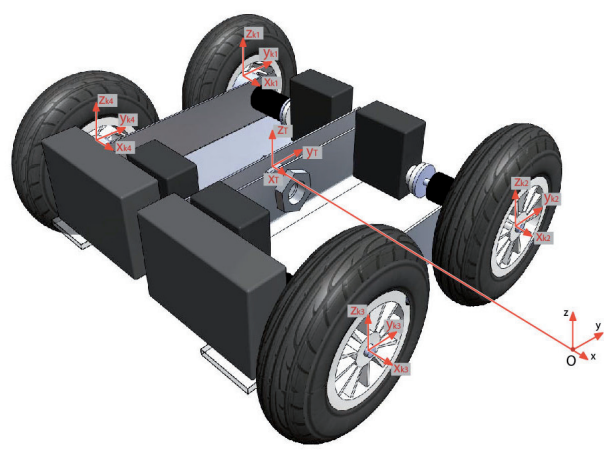

Fig. 3: Location of local coordinate systems in linkage.

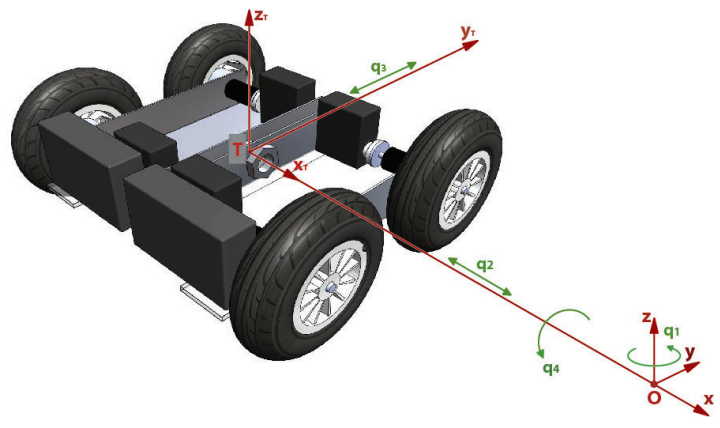

Fig. 4: Coordinates q1, q2, q3, q4 implementation.

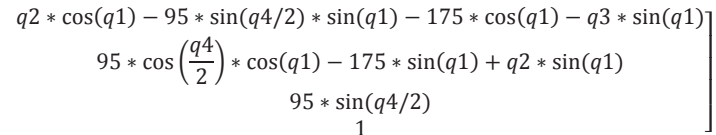

The same method we get position and velocity of center of gravity of chassis and wheels.

Based on constructed transformation matrices it is possible to construct simulation models for defining center of gravity geometric position of chassis and wheels in Matlab/Simulink environment.

Simulation model of position of geometric center of gravity of chassis and individual wheels comprises of several subsystems that have common input. Every subsystem represents position of wheel, or position of center of gravity to beginning $\mathrm{O}$ (Instantaneous Center of Rotation).

$T_{b 5}(q 1, q 2, q 3, q 4)=\left[\begin{array}{cccc}-\sin (q 1) & \sin (q 1) * \sin (q 3)-\cos (q 1) * \sin (q 3) & \cos (q 1) * \sin (q 3)+\cos (\mathrm{q} 3) * \sin (q 1) & 74 * \sin (q 1)-94 * \cos (q 1) \sin (q 1)-q 3 \cos (q 1)-q 2 \sin (q 1) \\ \cos (q 1) & -\cos (q 1) * \sin (q 3)-\cos (q 3) * \sin (q 1) & \sin (q 1) * \sin (q 3)-\cos (q 1) * \operatorname{soc}(q 3) & q 2 * \cos (q 1)-94 * \sin (q 1)-174 * \cos (q 1)-q 3 * \sin (q 1) \\ 0 & \sin (q 3) & -\sin (q 3) & 0 \\ 0 & 0 & 0 & 1\end{array}\right]$ 
Relationships for velocity of center of gravity chassis and wheels will get from assembled transformation matrix.

These derivatives are obtained using a matrix differential operator.

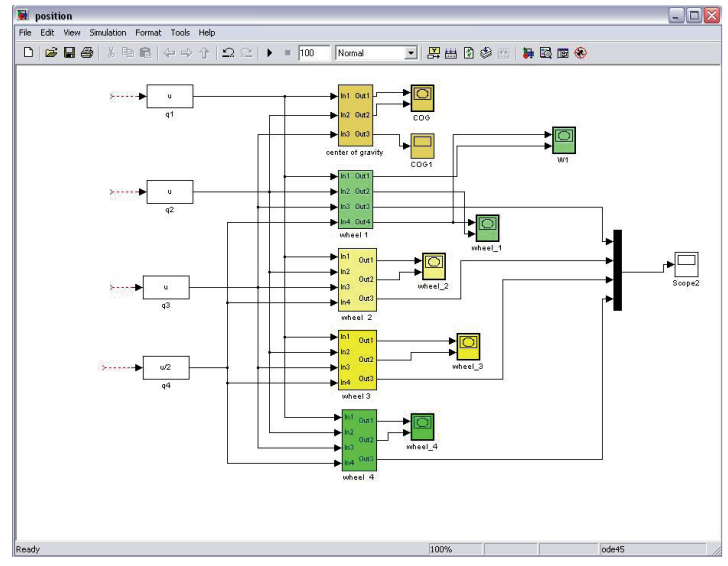

Fig. 6: Simulation model of position of center of gravity and wheels.

Layout representing velocity of individual chassis points consists of several subsystems, which represent velocities of wheels $1-4$ and chassis center of gravity.

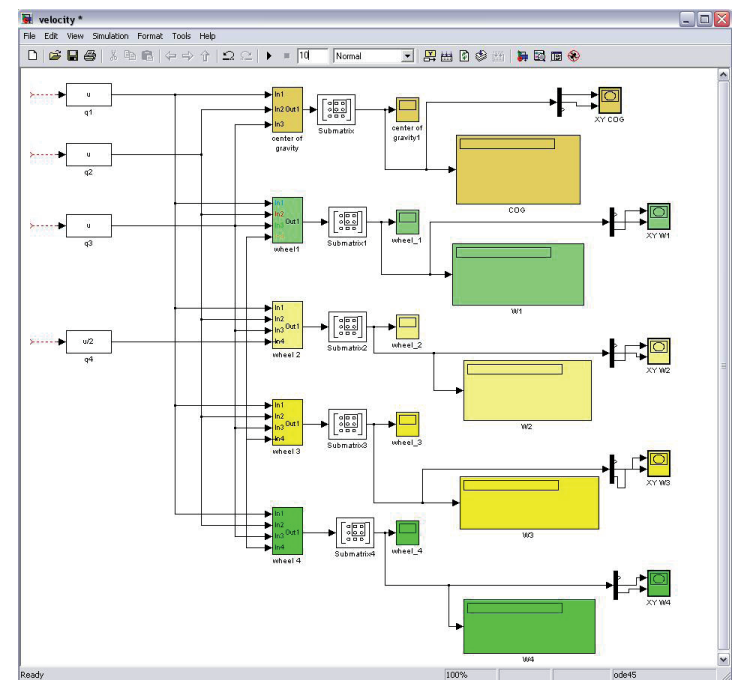

Fig. 7: Simulation model of velocity of chassis, center of gravity and wheels.

It is possible to use this simulation model to calculate estimated trajectory of center of gravity and wheels of chassis. It is also possible to examine behavior of model in any given combination of chassis dimensions. In connection to this there is also an option of chassis geometry optimization. Furthermore created model provides room for examining influence of terrain roughness on behavior of chassis of mechatronic system.

A significant asset is the option of testing model of such chassis composition of mechatronic system, what enables to find optimal chassis geometry in terms of various aspects of assessment before constructional vehicle solution itself.

\section{Conclusion}

The concept of control structure using kinematic and dynamic model at the same time provides the benefit of economical utilizing of energy sources. In terms of practical realization it is being considered to implement this structure into functional model, where this structure would in real time ensure chassis locomotion control of mobile mechatronic system. With this application the mobile mechatronic system gains a certain amount of intelligence. Hence it is possible to use the model for calculating estimated or requested trajectory of chassis center of gravity and wheels. At the same time it is possible to examine model behavior in any given combination of chassis dimensions and relating to this there is an option of chassis geometry optimization in terms of obstacles negotiability on diverse terrain.

\section{Acknowledge}

The paper was created in the frame of project "Center for research of control of technical, environmental and human risks for permanent development of production and products in mechanical engineering" (IMTS:26220120060) on the basis of operation program Research and development supported by European Regional Development Fund. .

\section{References}

[1] J. SMRČEK, L. KÁRNIK, "Robotics, Industrial robots, Desing -Construction - Solutions," Košice, 2008, ISBN 978-80-7165713-2

[2] R. GREPL, "Mechatronics-selected problems," Brno 2008, ISBN 978-80-214-3804-0

[3] R. GREPL, "Modeling mechatronics systems in Matlab SimMechanics," Praha, 2007, ISBN 978-80-7300-226-8

[4] R. GREPL, "Kinematics a dynamics mechatronics systems," Brno 2007, ISBN 978-80-214-3530-8

[5] M. NICULESCU, „Experiments in Mobile Robot Control," Mechatronics 2008

[6] V. BRÁT, "Matrix methods of analysis and synthesis of space 
committed mechanical systems," Praha, 1981

[7] L. GRACIA, J. TORNERO, „Kinematic control of wheeled mobile robots. Latin American Applied Research,.. Vol. 38, p. 7-16 (2008)

[8] CH. CHIH-FU, H. CHIN-I, F. LI-CHEN, "Nonlinear Control of a Wheeled Mobile Robot with Nonholonomic Constraints," IEEE International Conference on Systems, Man and Cybernetic, ISBN 0-7803-8566-7, p. 5404-5410

[9] E. IVANJKO,E. KOMSIC, I. PETROVIC, "Simple off-line odometry calibration of differential drive mobile robots," in Proceedings of 16th International Workshop on Robotics in Alpe-Adria-Danube Region, Ljubljana, Slovenia, june 7-9, 2007, p. 164-169

[10] L. JURIŠICA, A. VITKO, "Mechanics and robotics," AT\&P Journal 11/1998, p. 44-45. ISSN 1335-2237

[11] E. LUCET, Ch. GRAND, D. SALLÉ, P. BIDAUD, “Dynamic control of the 6WD skid-steering mobile robot RobuROC6 using sliding mode technique," The 2009 IEEE/RSJ International Conference on Intelligent Robots and Systems, October 11-15, 2009 St. Louis, USA

[12] J. ŠKARUPA, V. MOSTÝN, "Methods and tools of design industrial and service robots," Vienala Košice, 2002

[13] M. VALÁŠEK, ,Kinematics of robotic systems," 2011

[14] L. MIKOVÁ, M. KELEMEN, T. KELEMENOVÁ, "Four wheels inspection robot with differential wheels control," Acta Mechanica Slovaca, Roc. 12, c.3-B (2008), p. 548-558. - ISSN 1335-2393

[15] J. Haiyang, Z. Peng, H. Ying, Z. Jianwei, Z. Zhizeng, “Design and Kinematic Analysis of A Pedicle Screws Surgical Robot," Proceedings of the 2010 IEEE International Conference on Robotics and Biomimetics, December 14-18, 2010, Tianjin, China 